\title{
Sustain GEOBIM-a New Method to Simulate Sustainable Development Scenarios for Urban Areas
}

\author{
Heinz J. Bernegger ${ }^{1}$ (D) Patrick Laube ${ }^{2} \cdot$ Pascal Ochsner $^{2} \cdot$ Mihaela Meslec $^{1}$. \\ Hanno Rahn ${ }^{2} \cdot$ Johann Junghardt $^{2} \cdot$ Isabella Aurich $^{1} \cdot$ Simon Ashworth $^{1}$
}

Received: 5 January 2021 / Accepted: 8 July 2021 / Published online: 12 November 2021

(C) The Author(s) 2021

\begin{abstract}
In 2015, 193 member states of the United Nations (UN) signed the 2030 Agenda, entitled "Transforming Our World: The 2030 Agenda for Sustainable Development,". The planned implementation by 2030 , leaves only a decade to realize the 17 Sustainable Development Goals (SDG). Municipalities and cities constitute important stakeholders, who are obliged under SDG 11, to find ways to develop realistic solutions. Implementation and strategic planning require, among other things, new instruments to digitally model various sustainable development scenarios. Currently, however, it is still unclear what has to be modelled and how. What is clear is that sustainability and digitalization have to come together to deliver results. Several key challenges need to be overcome. First, is the heterogeneity of existing data and documents used in the built environment. Future solutions will depend on a combination of Building Information Modelling (BIM) and Geographic Information System (GIS). Second, is the merging of different existing data on an adequate level of abstraction which allows practical use of GIS and BIM data in a common model. Third, is the development of functioning, cost-effective workflows that will enable broad applications which adequately simulate specific sustainability aspects using spatial and temporal scenarios. This paper shows how these challenges can be systematically addressed in practice. It demonstrates which aspects of sustainability can be made visible and comprehensible for all stakeholders using only one single BIM- and GIS based data model. The proposed workflow could thus be considered as the basis for planning the next generation of smart and sustainable cities.
\end{abstract}

Keywords UN Agenda 2030 · GEOBIM · GIS · BIM · Sustainability · Digitalisation

Heinz J. Bernegger

heinz.bernegger@zhaw.ch

Extended author information available on the last page of the article 


\section{Introduction}

The 2030 Agenda SDG 11 "Make cities and human settlements inclusive, safe, resilient and sustainable" relies on private organisations, municipalities and cities as critical actors to ensure effective implementation and achievement of its set goals. The Real Estate (RE) industry in particular plays an important role in this context because it is the largest source of carbon emissions accounting for $40 \%$ of the total worldwide greenhouse gas emissions [12]. Moreover, it can be inferred from the emissions gap report released by the United Nations Environmental Program that the European RE industry is still far from meeting the global warming mitigation target set by the Paris Agreement at under $2{ }^{\circ} \mathrm{C}$ by 2050 [11].

Of the more than 2200 municipalities in Switzerland, only a few larger cities such as Zurich, Basel, Bern, Geneva, or Lausanne have a more comprehensive sustainability strategy. Around $60 \%$ of the Swiss population already lives in more than 460 municipalities that are certified as "Energy Cities" [7], One of the main reasons for this very high number is that there has been an extremely strong focus on the subject of energy efficiency in Switzerland over the past 2 decades. In Switzerland, over 51,000 buildings have so far been certified with the Minergie passive house standard [8]. However, the 2030 Agenda encompasses much more than just the issue of energy efficiency.

A major challenge in implementation of the 2030 Agenda is the heterogeneity and multiplicity of the associated SDG goals and sub-goals. In practice, this means that many actors in the RE industry, such as investors, developers, owners, and portfolio holders, are unclear about what actions they can take to contribute to the SDG. In order to proactively manage the main influencing factors, a high degree of transparency is necessary as to which topics and information are already are possible to promote, Stakeholders need clarity regarding the quality of information and how it can be specifically analysed and used for a sustainability assessment. Due to these difficult framework conditions, the question arises how the analysis of relevant sustainability aspects can be digitally supported in order to reduce the time required, the complexity, and the resulting costs. This is the starting point for the concept described below to develop a workflow tool for the automated analysis and visualisation of important sustainability aspects in new construction projects as well as in portfolios of existing buildings. To achieve the research aim, existing digital data sources from the built environment GIS and BIM are intelligently connected and used.

\section{Problem Definition}

If existing GIS and BIM data sets are to be combined and made usable, further challenges arise in practice:

a) If entire building portfolios, areas, or quarters are to be analysed, the first challenge is the heterogeneity of the existing data and documents. In contrast to an industrial process where exact copy parts can be repeatedly manufactured, each building is usually unique and as such a prototype in its own right. To realise their creation, a diverse range of different experts, planners, and specialists need to be involved. In today's world, this also requires an increasing number of software products and data formats. 
At data level, the heterogeneity of BIM and GIS information identified in literature originates from various sources such as the definition of reference systems, level of detail, granularity or geometry [3]. Other integration challenges appear at process level and at the application level [1] of transforming the GIS and BIM data into knowledge needed in various stages of the building life-cycle [6].

b) Merging a multitude of existing data to an appropriate and uniform level of abstraction presents its own challenges. The interfaces and integration aspects between these sources are keys to meeting the goal to use GIS and BIM data in a common "Sustain GEOBIM model" in the future.

The state of the art research on BIM-GIS integration and interfaces addresses the importance of developing new standards and models to bridge the gaps between the two domains [4]. Up until now, Industry Foundation Classes (IFC) and CityGML are the main standards in BIM and GIS domains. Other research steps need to be made to extend the existing standards to support the conversion and translation of models in the BIM-GIS integration process $([6,10]$.

c) Key to the success is developing a functioning and cost-effective analysis workflow that can be widely used in the future to adequately model and simulate certain sustainability aspects using spatial and temporal scenarios.

The industry and research community has recognised the value of integrating GIS and BIM environments for supporting the decision-making process over the entire life-cycle of real estate portfolios. As a consequence, some efforts have been made to develop conceptual methods and tools to address some of the challenges such as data conversion, georeferencing, or data heterogeneity. However, up to now, there are no clear rules and solid technological solutions to support the full integration [9].

\section{Research Question}

The overarching research question is: How can existing data from GIS and BIM be used to optimally analyse, model, simulate and visualise key sustainability aspects such as resource efficiency, climate resilience, recyclability and environmental protection?

\section{Methodology}

The methodological procedure for developing an optimised workflow tool is divided into the following work steps:

a) The first step is a basic analysis to clarify the question of what contribution RE can make to the 17 goals of the 2030 Agenda. This includes assessing how criteria from existing sustainability assessment tools can be thematically assigned to the SDG. In the context of this basic analysis, various Swiss and international instruments are examined. It was decided to focus on the Swiss DGNB system of the SGNI, because the DGNB system enjoys broad international recognition and includes an intelligent, holistic and comprehensive system approach.

b) As a second step, it is investigated for which of the identified sustainability aspects GISbased data or data sources exist in Switzerland that could be used directly or indirectly for 
a criteria-based sustainability assessment. Here, a distinction is made in the availability of data sets at (a) national, (b) regional (or at cantonal level), and (c) local (at the level of individual municipalities).

c) As a third step, criteria from the Swiss DGNB system were assessed to establish which could be supported using the BIM process when facilitating a corresponding assessment. A distinction is made as to which information is already available as standard in BIM models and, which of the aspects examined could be modelled and visualised in a BIM model at all.

d) In the final step, it was investigated which import and export functionalities exist between BIM-based and GIS-based software solutions and for which use cases (circularity, mobility, biodiversity, etc.). This included considering which workflows are best suited to generate a superordinate overall model.

\section{Technical Realisation}

Currently, the main national and international research interest in BIM as a method lies in its optimised use in larger new-build construction projects. A major challenge, especially in OpenBIM projects, is the coordination of the software solutions involved, whereby a standardised and object-oriented IFC interface solution is usually used in new construction projects. While BIM and GIS originally developed in their own application areas of planning/ architecture and environmental/spatial analysis, respectively, intensive work is currently being done on integrating the two methodologies in software development and application [6]. GeoBIM systems that cross system boundaries promise novel approaches for the sustainable development of the built and designed environment, combining the detailed CAD models from architecture with the multi-layered geodata on the buildings' surroundings with considerable added value. While first realised projects show the potential of GeoBIM solutions [5], comprehensive universal models like the envisaged "Sustain GEOBIM model" are largely missing.

With regard to sustainable development, a particular challenge is the question of a suitable approach for defining existing properties and areas. Here, compared to classic new construction projects, there are further challenges in practice. The classic starting point for existing buildings is a large heterogeneity and diversity of scattered data, information, documents, plans, and 3D models, which must be brought together to form a uniform overview or model. Only through such holistic models can sustainable development scenarios be modelled in such a way that they can also develop a sustainable significance [2]. It is the required integration of heterogeneous data sources via the common spatial reference that constitutes a classic strength of GIS. Developed from the 2.5-dimensional map perspective (2D space plus a single elevation information), conventional GIS solutions, on the other hand, are weaker in handling 3D information. The industry has recognised this weakness and is currently working hard to integrate GIS and BIM coined as GeoBIM solutions [13]. The existing challenges differ depending on the depth of integration [6]: Full integration at the data level aims at a single fused dataset of CAD, BIM, and GIS data. This requires profound transformations of all data sets. In the case of integration at process or application level, CAD/BIM and GIS systems remain separate, but allow analysis and visualisation processes that cross system boundaries. BIM-GIS integration also poses different challenges for software interfaces and workflows, 
depending on whether unidirectional (GIS data in target system BIM or BIM data in target system GIS) or bidirectional integration is required [6].

As stated by Noardo et al. [9], even as technical solutions are evolving very fast to support the BIM-GIS integration, there is a need for new processes in RE organisations to support the change towards using integrated GeoBIM information instead of separate data sources.

\section{Results}

It is a challenge to assess the potential impact of the RE sector on the achievement of the Agenda 2030 goals. The current focus is clearly on the development of a comprehensive $\mathrm{CO}_{2}$ balancing methodology over the entire life cycle of RE and the associated built environment. Well-developed instruments for measurement and calculation already exist in this area. For many of the other topics addressed by the SDGs, there are still no standardised methods for impact measurement and calculation. Within the framework of the development project presented here, a pragmatic approach is therefore pursued not to invent new instruments at the level of buildings and sites, but to seek a direct reference to existing and proven sustainability assessment systems and to build on these with regard to the underlying systematics.

Table 1 shows the SDG12 "Responsible consumption and production - Ensure sustainable consumption and production pattern".

This list shows the complexity of the aspects that result from the reference to only one of the 17 SDGs.

In the context of this paper, the project results to date can only be shown exemplary with regard to the reference to existing assessment systems. This is illustrated below. The following assessment is based on the analysis of 21 large Swiss construction projects with a total floor area of over $700,000 \mathrm{~m}^{2}$, which have been certified or are in the process of being certified with the Swiss DGNB System of the SGNI in the past 10 years.

Table 2 illustrates criteria from the SGNI/DGNB assessment system which are deemed relevant to the circular economy (column 2) in line with SDG 12 (Ensure sustainable consumption and production patterns). Where specific criteria are deemed relevant; the maturity of how BIM/GIS can be used in a supporting role is indicated in columns 3 and 4 .

\section{Discussion}

In the context of the Sustain GEOBIM project, the possibilities for digitally supporting the sustainability assessment of individual properties as well as entire areas and neighbourhoods to support the 2030 Agenda are being systematically tested. The basic analysis of the relations already clearly shows that various topics of the SDGs manifest themselves differently, but mostly in a very broad and multifactorial manner in the criteria of established building assessment systems such as the DGNB system. By showing the assignments, the relevance of the SDGs in the sustainability assessment of real estate can be made comprehensible.

The use of BIM data sets can be of great benefit in new construction projects and supports the efficiency of the assessment for a large part of the criteria and thus becomes the basis of the BIM-based certification of the future (Fig. 1). 
Table. 1 Real estate-related sustainability aspects at SDG12

12.1: 10-year planning: not directly supported

12.2: Promote sustainable management and efficient use of natural resources

12.2.1 Use renewable resources

12.2.2 Responsible resource extraction

12.2.3 Optimisation of land use

12.2.4 Optimisation of conversion and transformation capacity

12.2.5 High deconstruction \& recycle \& reuse capacity

12.2.6 Ensure sustainability aspects in tendering and contracting.

12.2.7 Documentation for sustainable management

12.2.8 Quality assurance during construction

12.2.9 Orderly commissioning for optimised operation

12.3: Reduction of food waste (substitution as an indirect support measure)

12.3.1 Enabling food production in the immediate vicinity of the building (indirect support)

12.3.2 Use of locally produced food (indirect support)

12.4: Environmentally sound chemical management (reduction of harmful substances in material flows)

12.4.1 Reduction of risks to the (local) environment

12.4.2 Reduction of risks for building occupants (e.g. VOC via indoor air)

\section{5: Reduction of waste generation}

12.5.1 New construction: High deconstruction and recycling friendliness

12.5.2 New construction: Use of renewable raw materials (e.g. wood) and use of renewable energies

12.5.3 Operation: Optimised management of recyclable materials in operation (zero-waste target)

12.5.4 Transformation (refurbishment/conversion/deconstruction): Optimised management of recyclable materials in construction

12.5.5 Products/constructions: Dismantling capability, separability of the material fractions

12.5.6 Products/installations/construction: Durability (no foreseeable weak points) and timelessness (no fads in design)

12.5.7 Products/fittings/construction: High usability (universal design guidelines)

12.6: Promotion of sustainable production methods, environmental management and CSR reporting

12.6.1 Implementation of monitoring processes (material/substance flow analyses)

12.6.2 Life cycle assessment of buildings (new construction, conversion, deconstruction)

12.6.3 Life cycle assessment of operation

12.6.4 Implementation of continuous reporting procedures

12.7: Promotion of sustainable procurement

12.7.1 Sustainable procurement guidelines for new buildings

12.7.2 Sustainable procurement guidelines for operation

12.7.3 Information transparency over the entire real estate life cycle

12.7.4 Information transparency across all organisational levels

12.8: Promotion of sustainability understanding \& awareness (circular thinking)

12.8.1 Integration of circular thinking into strategy processes

12.8.2 Integrate circular thinking into planning processes

12.8.3 Integration of circular thinking into operational implementation processes

12.8.4 Training programmes for employees

In the Swiss DGNB system of the SGNI, 47 of the 51 sustainability criteria can be partially supported with BIM such as the automatic identification of building components, the quantification of spaces, masses, and quantities that can be automated, the visualisation of design qualities, the provision of evidence through simulations and automated functional queries, or through the output of building product-related meta-information. In new construction projects, GIS information is particularly important for the site criteria (SITE) with regard to the analysis of environmental hazards, site-related synergy potentials, transport connections, and locally available infrastructures. In terms of GIS, 15 of the 51 DGNB sustainability criteria of the SGNI can be partially supported. In the future, however, GIS-based data sets will play an increasingly important role, especially in the analysis of existing building portfolios and in the analysis of entire sites and neighbourhoods. In Switzerland, there are a large number of usable 
Table 2 Relationship between SGNI/DGNB criteria related to the circular economy and supported by BIM/GISI

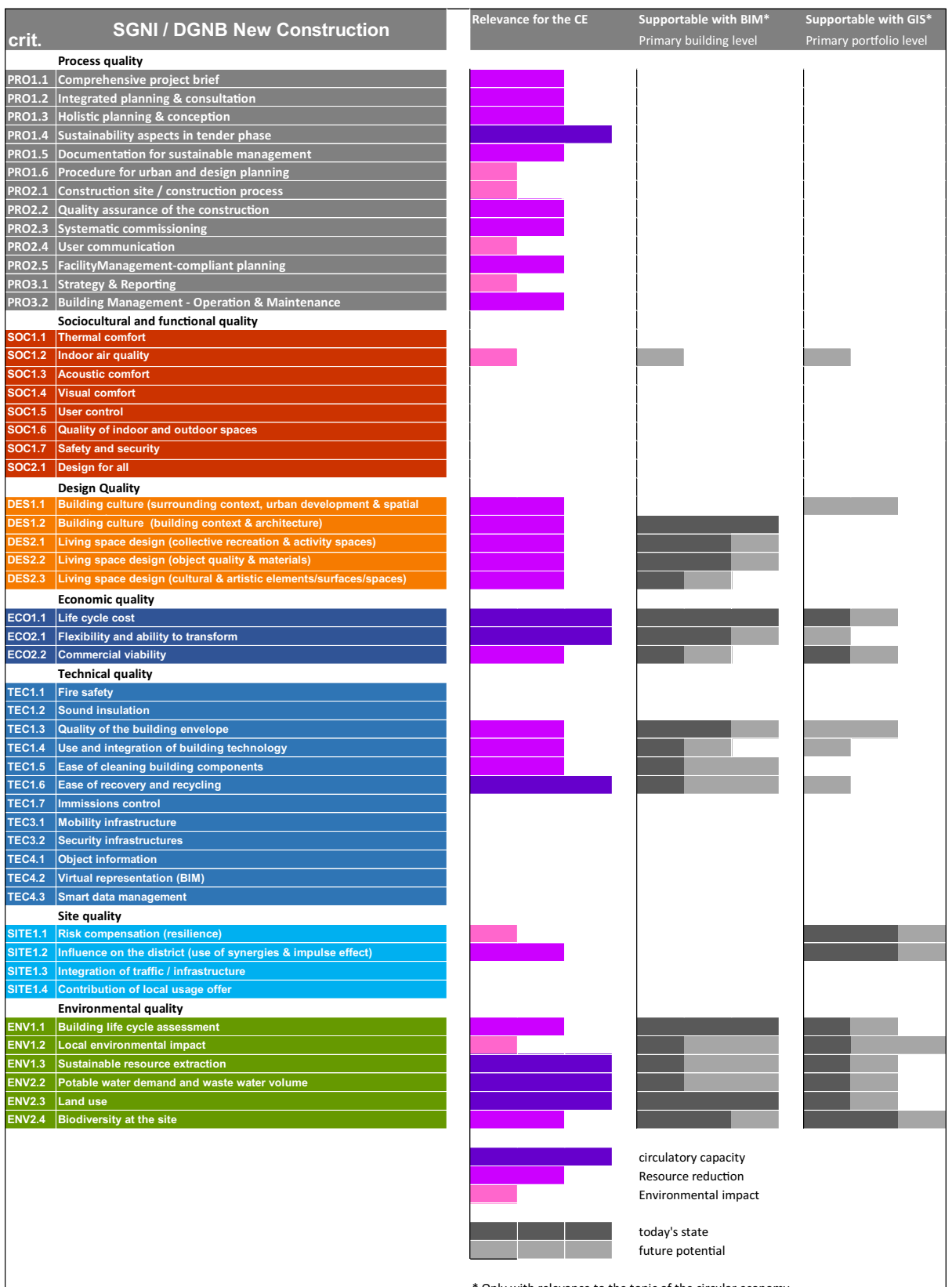

* Only with relevance to the topic of the circular economy

GIS-based databases and information sources for this purpose. Within the scope of the project analysis, 81 data sets were analysed for three selected areas, of which two contained local, 24 regional and 55 national data. Since the analysed data sets were not created specifically for the sustainability assessment of RE, it is often not possible to directly assess the degree of 


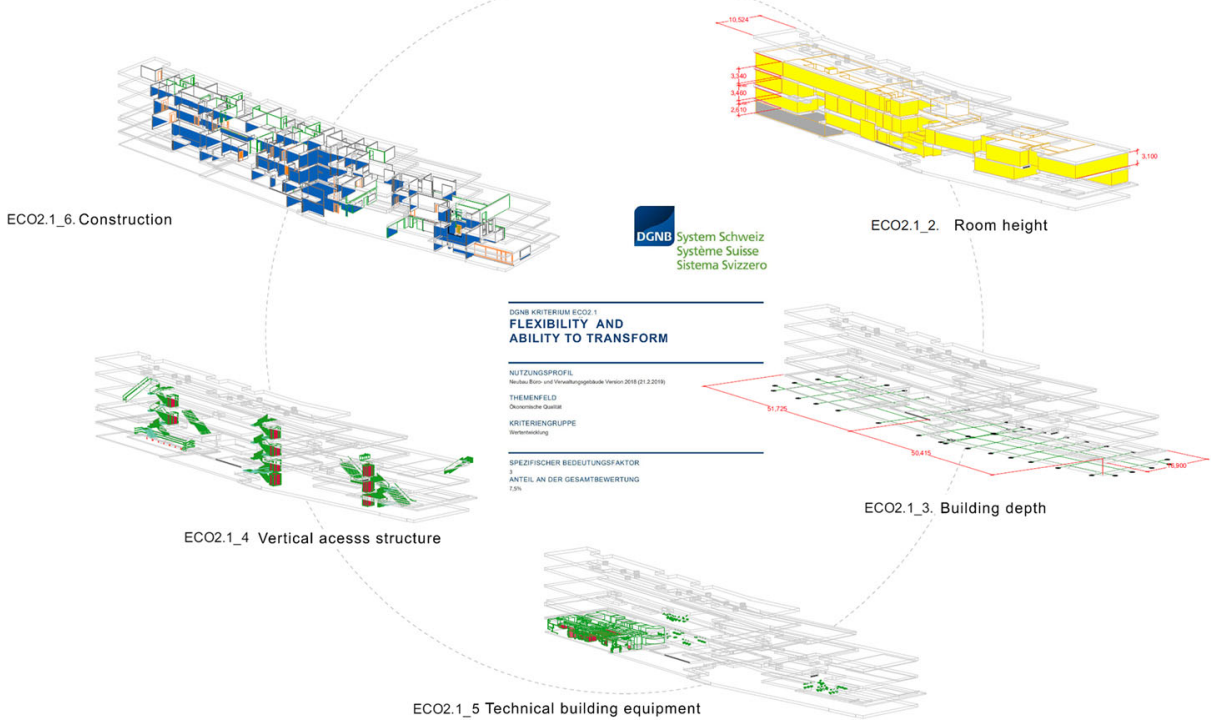

Fig. 1 BIM-based visualisation of building-related flexibility aspects in the Swiss DGNB system of the SGNI

fulfilment of a specific criterion. Nevertheless, meaningful assessments can be generated by simplifying the assessment and making additional assumptions. Based on this, conclusions can be made as to how the existing GIS data sets could be enriched with additional data to ensure they can be used for more precise sustainability assessments in the future. Moreover, GeoBIMbased real estate development has the capacity to bring together the sustainability information from very specialised niche areas in a very fragmented industry.

\section{Conclusion}

The results from the analysis of the buildings and sites in the context of the project work indicated that not only the vast majority of the 51 sustainability criteria and a total of 343 indicators of the Swiss DGNB system of the SGNI can be supported through the use of BIM or GIS data sets, but that this information can also be used to visualise the sustainability characteristics of the corresponding buildings or sites. It should be noted the results only apply to the analysed DGNB system and do not ensure direct transferability to other international assessment instruments such as LEED or BREEAM.

Another goal of the project is to find simple ways to support stakeholders by making as many of the relevant sustainability aspects as possible easy to visualise in a common overall Sustain GEOBIM overall model via a "lean" workflow. This would combine all relevant sustainability information from the BIM and GIS perspectives. If the underlying data sets are available over longer periods of time, they can also be used to retrospectively analyse local development processes with regard to the sustainability of the corresponding development dynamics for specific criteria. These also form the basis for modelling future development scenarios. This will enable completely new types of collaborative planning processes in the 
future with the help of virtual and mixed reality technologies, which are to be tested and optimised within the framework of the project.

Author Contribution Heinz J. Bernegger led the paper writing with substantial contributions from all coauthors who helped to conceive the paper and manage revisions.

Funding Open Access funding was provided by ZHAW Zürcher Hochschule für Angewandte Wissenschaften. The GeoBIM project is financed by the Zurich University of Applied Science (ZHAW) to support multidisciplinary and international research on environmental issues (Campus@LSFM, project duration 2020-2021).

Availability of Data and Material Not applicable.

Code Availability Not applicable.

\section{Declarations}

Conflict of Interest On behalf of all authors, Heinz J. Bernegger as the corresponding author declares that there is no conflict of interest.

Open Access This article is licensed under a Creative Commons Attribution 4.0 International License, which permits use, sharing, adaptation, distribution and reproduction in any medium or format, as long as you give appropriate credit to the original author(s) and the source, provide a link to the Creative Commons licence, and indicate if changes were made. The images or other third party material in this article are included in the article's Creative Commons licence, unless indicated otherwise in a credit line to the material. If material is not included in the article's Creative Commons licence and your intended use is not permitted by statutory regulation or exceeds the permitted use, you will need to obtain permission directly from the copyright holder. To view a copy of this licence, visit http://creativecommons.org/licenses/by/4.0/.

\section{References}

1. Amirebrahimi S, Rajabifard A, Mendis P, Ngo T (2015) A Data Model for Integrating GIS and BIM for Assessment and 3D Visualisation of Flood Damage to Building. 12

2. Arroyo Ohori K, Diakité A, Krijnen T, Ledoux H, Stoter J (2018) Processing BIM and GIS models in practice: experiences and recommendations from a GeoBIM project in the Netherlands. ISPRS Int J Geo Inf 7(8):311

3. Beck F, Borrmann A, Kolbe TH (2020) The need for a differentiation between heterogeneous information integration approaches in the field of "bim-gis integration": a literature review. ISPRS Annals of Photogrammetry, Remote Sensing and Spatial Information Sciences VI-4(W1-2020):21-28. https://doi. org/10.5194/isprs-annals-VI-4-W1-2020-21-2020

4. de Laat R, van Berlo L (2011) Integration of BIM and GIS: The development of the CityGML GeoBIM Extension. In: Kolbe TH, König G, Nagel C (eds) Advances in 3D Geo-Information Sciences (pp. 211225). Springer. https://doi.org/10.1007/978-3-642-12670-3_13

5. Ellul C, Stoter JE, Harrie L, Shariat M, Behan A, Pla M (2018) Investigating the state of play of geoBIM across Europe. The International Archives of the Photogrammetry, Remote Sensing and Spatial Information Sciences, Volume XLII-4/W10, 2018, 13th 3D GeoInfo Conference, 1-2 October 2018, Delft, The Netherlands

6. Liu X, Wang X, Wright G, Cheng JC, Li X, Liu R (2017) A state-of-the-art review on the integration of Building Information Modeling (BIM) and Geographic Information System (GIS). ISPRS Int J Geo Inf 6(2):53

7. EnergieSchweiz (2021) Neustart Energiestadt. https://www.local-energy.swiss/neustart-energiestadt.html

8. Minergie (2021) Minergie Gebäudeliste. https:/www.minergie.ch/de/gebaeude/gebaeudeliste 
9. Noardo F, Harrie L, Arroyo Ohori K, Biljecki F, Ellul C, Krijnen T, Eriksson H, Guler D, Hintz D, Jadidi MA, Pla M, Sanchez S, Soini V-P, Stouffs R, Tekavec J, Stoter J (2020) Tools for BIM-GIS Integration (IFC Georeferencing and Conversions): Results from the GeoBIM Benchmark 2019. ISPRS Int J Geo Inf 9(9):502. https://doi.org/10.3390/ijgi9090502

10. Song Y, Wang X, Tan Y, Wu P, Sutrisna M, Cheng JCP, Hampson K (2017) Trends and opportunities of BIM-GIS integration in the architecture, engineering and construction industry: a review from a spatiotemporal statistical perspective. ISPRS Int J Geo Inf 6(12):397. https://doi.org/10.3390/ijgi6120397

11. UNEP (2019) The emissions gap report 2019. United Nations Environment Programme.

12. UNEP (2020) 2020 Global status report for buildings and construction: towards a zero-emissions, efficient and resilient buildings and construction sector. https://globalabc.org/sites/default/files/inlinefiles/2020\% 20Buildings\%20GSR_FULL\%20REPORT.pdf Access Date" of 21 June 2021

13. Wang H, Pan Y, Luo X (2019) Integration of BIM and GIS in sustainable built environment: a review and bibliometric analysis. Autom Constr 103:41-52

\section{Affiliations}

\section{Heinz J. Bernegger ${ }^{1} \cdot$ Patrick Laube ${ }^{2} \cdot$ Pascal Ochsner $^{2} \cdot$ Mihaela Meslec $^{1} \cdot$ Hanno Rahn $^{2} \cdot$ Johann Junghardt ${ }^{2} \cdot$ Isabella Aurich $^{1} \cdot$ Simon Ashworth $^{1}$}

1 Department Life Sciences and Facility Management, Institute for Facility Management, ZHAW Zurich University of Applied Sciences, Grüentalstrasse 14, 8820 Wädenswil, Switzerland

2 Departement Life Sciences and Facility Management, Institute for Natural Resource Sciences, Zurich University of Applied Science, Grüentalstrasse 14, 8820 Wädenswil, Switzerland 